\title{
Comentarios estimulados por la lectura del artículo "Educação PERMANENTE em Saúde: desafio ambicioso e necessário"
}

Mario Rovere

En principio quiero explicitar que estoy analizando este trabajo (lamentablemente solo puedo hacerlo en español) con una gran simpatía por el tema, por el autor y por el artículo lo que tal vez dificulte mi tarea de "debatedor".

Mi intento de deconstrucción siguió un poco el método salvaje de marcar el texto a medida que lo iba leyendo, así que voy a seguir el orden del propio artículo y compartir lo que más me movió a reflexión, me hizo sobresaltar o me generó entusiasmo. Me anticipo a comentar que algunas dudas que me surgieron al principio del documento son contestadas en párrafos posteriores pero me parecieron útiles para contribuir al debate.

El propio autor invita a que el texto "cumpra a função de estabelecer um debate", y ese debate comienza para mí en la colocación de la Educación Permanente en Salud (EPS) como un marco que absorbe las diferentes formas de educación en el sector.

¿Es, entonces, la Educación Permanente un nuevo modelo educacional que puede permear cualquiera de las prácticas educativas? ¿Desde la formación de grado hasta la educación continua promovida por las corporaciones? o es por su esencia aprendizaje en servicio al ser necesariamente situada en los escenarios de los servicios de salud cualesquiera sean ellos.

O más bien necesitaríamos dos conceptos enlazados uno que exprese las dimensiones emancipadoras del modelo educacional y otro el carácter situacional del aprendizaje en los propios escenarios laborales de los servicios de salud en todas sus dimensiones (quizás conectado con los Institucionalistas aunque estimo que esta perspectiva está mucho menos trabajada por la conceptualización que la OPAS realizó sobre la EPS). Allí el conector para "a noção de auto-análise e autogestão" podría ser la propia dimensión problematizadora aportada por Freire que lleva a la formulación "educación en el trabajo, a través del trabajo y para el trabajo" (Rovere, 1995, p.70) .

En relación con el propio "Exercício da Educação Permanente em Saúde" parece extraño comenzar las motivaciones por la velocidad del conocimiento porque es una motivación habitual para las formas clásicas de educación en el sector.

Tal vez la Educación permanente de trabajadores, equipos y redes de equipos desencadene sus motivaciones, mas bien en cierta insatisfacción profunda con ese caudal de conocimientos e innovación que fortalece la atención de la salud como mercadería a ser transada en el mercado de servicios de salud y reacciona frente a la despreocupación por pensar la integralidad de los problemas de salud y de las respuestas que trabajadores de salud y población requieren construir juntos para enfrentar la complejidad creciente de los problemas sociales y sanitarios.

${ }^{1}$ Coordinador de la Maestría de Salud Pública, Universidad de Buenos Aires. <mrovere@fibertel.com.ar>

Av. Elcano, 3207

Buenos Aires, Argentina ZIP 1426 


\section{DEBATES}

Tal vez las ambiciosas iniciativas de transformación en realidad marcan y demarcan un campo de fuerzas que debe ser constantemente cartografiado para que la educación permanente no sea reabsorbida como una metodología moderna y eficiente para aprender lo mismo. Estamos insinuando una transformación en la cultura de salud en la que la EPS es al mismo tiempo método y contenido portador de nuevas formas de resolver los problemas de salud.

Así se entiende el dilema de hierro planteado por el autor "ou constituímos coletivos de trabalho ... orientadas pela sempre maior (y diferente) resolutividade dos problemas de saúde ou colocamos em risco.... a qualidade de nosso trabalho" (y la salud de la población).

Un nuevo desafío llega en el siguiente párrafo ya que a pesar de la referencia a los saberes tradicionales me parece que siempre en cualquier cultura y en cualquier sector social la "produção de sentidos ligada ao processo saúde-doença-cuidado-qualidade de vida pertence a lógicas distintas do modelo racional científico vigente entre os profissionais de saúde." El problema es cuando la clínica queda atrapada en un molde cientificista reforzada por un modelo de gestión fabril que la transforma en mercadería.

En referencia a si la EPS es una actividad medio, creo que el debate continúa a través de los años Educar para Transformar - Transformar para Educar es el título de un libro de Nuñez que creo que sirve para dejar abierta esta polaridad.

Comparto que la lógica de Recursos Humanos es un gran límite y que puede perfectamente ser asociado a un factor productivo. Sin embargo vale la pena recordar que al menos en español el concepto de formación es elegido casi en un sentido inverso para contestar las tendencias mas conductistas o "behavioristas" del entrenamiento, de la capacitación y del adiestramiento. Formación así remite a formación integral de una persona para liberarla de los aprendizajes utilitarios para que se contacte con el saber universal y desarrolle su potencial de aprender a aprender.

A mí también me parece "impostergável assegurar à área da formação, então, não mais um lugar secundário ou de retaguarda, mas um lugar central, finalístico" creo yo un espacio de formación de militantes por el direito a saude. Al respecto Tenti Fanfani observa que en su origen la palabra "pro fe sional", como la palabra "pro fe sor" deriva de la raíz latina profesare, es decir que el profesional no se define tanto como aquel que detenta el monopolio de un saber, de un campo de conocimiento o de un conjunto de técnicas sino como quien tiene un compromiso con un objeto y con su transformación.

En la salida de los trabajadores de su posición de "recursos humanos" a actores sociales no hay que olvidar, como se señala mas adelante, que "los sujetos están sujetados"; sujetados a modelos de formación, a modelos de práctica, a modelos de gestión, en definitiva a un "habitus" como diría Bourdieu no es sencillo ni depende solo de un acto de voluntad. Esta transformación es compleja y profundamente social ya que incluirse en las luchas por el derecho a la salud requiere condiciones y tiempos de maduración.

También coincido en que la Educação Permanente em Saúde seria (o más bien es) "uma estratégia fundamental para a recomposição das práticas..." de una larga lista de procesos educativos en la que solo agregaría a la propia educación popular en salud, tal como algunos países (por ejemplo Bolivia) han incluido, sobre la base del mismo paradigma educacional que la EPS.

En relación con la "Formação para a Educação Permanente em Saúde" yo agregaría, para caracterizar el campo de fuerzas, la influencia que ha tenido en el pensamiento y la práctica de la administración hospitalaria el management americano muy teñido de 
${ }^{2}$ Agentes de propaganda de los laboratorios farmacéuticos. improntas fabriles. En tiempos bastante recientes aun se podía escuchar en América Latina "en última instancia un hospital es una fábrica de consultas y egresos". Esta imagen aun no ha sido totalmente desalojada ya que los sistemas de estadísticas de hospitales refuerzan una verdadera obsesión por el productivismo en los servicios de salud.

Por eso resistir a la línea prescriptiva de los especialistas es difícil, porque el modelo de gestión fabril los refuerza y además porque muchos de ellos se encuentran directa o indirectamente estimulados por el propio "complejo médico industrial" que financia una buena parte de las actividades científicas, congresos, investigaciones y publicaciones.

En tal caso no pude dejar de recordar una historia real que me sucedió durante una supervisión en el Norte de la Argentina cuando el único médico a cargo de una estación sanitaria me decía "y como quiere que me capacite si aquí no llegan los visitadores médicos"

La noción de proceso y de difusión reticular de la educación permanente constituye una descripción muy ajustada pero talvez valdría la pena discutir sobre los aspectos de sustentabilidad de la propia educación permanente y de la necesidad de agentes internos o externos que dinamicen y hagan circular.

La concepción de una fuerza laboral activa y movilizada por la calidad de los servicios y la equidad en la atención es una imagen que ayuda a dar visibilidad positiva al personal de salud.

En referencia al "Quadrilátero da Formação" me parece un dispositivo muy interesante e ingenioso para conectar procesos que suelen pensarse por separado. Coincido en que "tomar o cotidiano como lugar aberto à revisão permanente e gerar o desconforto com os lugares como estão/como são", constituye la principal motivación de los procesos de aprendizaje de la EPS.

La idea de abandonar (desaprender) o sujeito que somos para ser "produção de subjetividade: todo o tempo abrindo fronteiras, desterritorializando" dista de ser un párrafo más y menos aun una conclusión, instala un aumento del voltaje que en cierta forma fuerza a revisitar el documento desde su comienzo.

Al hacerlo siento que el propio autor - en consistencia con la propia EPS - se ha ido desplazando durante la escritura para proponernos sobre el final una acción contrahegemónica, que incluye mecanismos que pueden liberar a la propia educación permanente - al mismo tiempo permanente y situacional (aqui-e-agora) - hoy capturada desde todos los vértices del cuadrilátero.

De ese tamaño es nada menos la dimensión del desafío.

\section{Referências}

ROVERE, M. Gestión estratégica de la Educación Permanente. In: HADDAD, J.; ROSCHKE, M.; DAVINI, C. (Orgs.) Educación permanente en salud. Washington: OPAS, 1995. p.63-109.

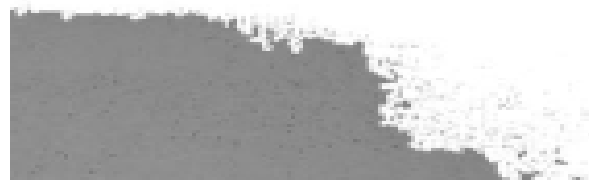

